\title{
How Cinema Sounds Affect the Perception of a Motion Picture
}

\author{
Andreas G. Anestis ${ }^{1,2, *}$, Christos A. Gousios ${ }^{1}$ \\ ${ }^{1}$ Department of Film Studies, School of Fine Arts, Aristotle University of Thessaloniki, Greece \\ ${ }^{2}$ Division of Technology and Science, The American College of Thessaloniki, Greece
}

Copyright $(\subset 2015$ by authors, all rights reserved. Authors agree that this article remains permanently open access under the terms of the Creative Commons Attribution License 4.0 International License

\begin{abstract}
The object of the present study was to investigate the effects of sound on the perception of motion pictures by film viewers. For this purpose, we selected a sequence from the film "Elephant" (G. Van Sant, 2003) and composed two alternative soundtracks. The three different versions of the sequence (one with the original soundtrack and two with the alternative ones) were screened to 51 adult students (mean age 21.3 y.o.), who answered a series of questions after each screening. We concluded that different soundtracks change the perception of the audience mainly concerning the recognition of the film gender and the emotions that the viewers develop while watching the sequence. Moreover, the sound-design can possibly create visual illusions when the source of sound is shown on screen. Finally, factors like the sex and the field of studies seemed to differentiate our results, thus revealing their potential effect on the viewer's perception.
\end{abstract}

Keywords Motion Pictures, Viewers' Perception, Psychoacoustics, Sound Design

\section{Introduction}

The ability of our organism to receive, translate and respond to environmental stimuli, mainly visual and auditory, has been crucial during the evolution of the human species and always maintains its great importance for its survival. In our days, a "civilization of the image" is established and motion pictures consist one of its major aspects. Filmmakers have developed methods and techniques to engage their audience, driving their attention and emotions. The effects of movies experience on our society and culture have many times been questioned by philosophers, film-makers, film-theorists, and psychologists [1].

Since the process of environmental stimuli perception has a neurological basis, brain scientists have also recently considered the nature of movies experience. An important number of studies during the last 50 years have investigated the mechanisms of the human nervous system that coordinate the reception of various environmental stimuli in order to create what the individual understands as "reality". In general, older studies supported the idea that vision is dominant between the five senses in this "reality-building" brain process $[2,3]$. However, recent papers conclude that there is a balance between vision and audition [4-9] and probably a cross talk between these two sensory pathways [10]. The development of methods for screening brain activity has permitted the identification of brain areas that are implicated in the process of interacting between visual and auditory stimuli [11] contributing to linking brain with mental processes.

Despite the scientific interest for the film viewer's brain activity, the movie experience hadn't, till recently, been approached by empirical interdisciplinary research. Shimamura [1] introduced the term "psychocinematics" to describe the scientific analysis of the aesthetic nature of movies by scientists, philosophers, filmmakers, sociologists, psychologists and other related endeavors, as a "holistic" approach to the phenomenon of cinematic perception. Concerning specifically the sound, one of the two major qualities of the cinematic reality, psychoacoustics tries to investigate the mechanisms of sound perception from the human brain [12]. In contrast to acoustics that study the physical and measurable parameters of sound waves (wavelength, frequency etc), psychoacoustics refer to subjective sound features including loudness, pitch, tempo, and melody and to all the different kinds of their effects, thus contributing in revealing the different aspects of sound as a stimulus [13-18].

Taking into account the great range of effects of the various sound features on the listener, as well as the importance of both audition and vision in constructing a common audiovisual reality [19-20], it is of great importance to identify the relation between sound and image in the case of film synthesis, since cinema is exactly what we call an "audio-visual art". More specifically, in this study we aim to focus on the effects of different sound designing on the perception of a motion picture. Our main purpose is to try to 
answer the following two questions: (1) can we change the viewers' perception of the film's gender or dramatic elements (crucial moments, protagonist feelings), by performing changes in the sound band? (2) are there any differences in the perception of the above elements between different groups of viewers? As far as we know, this is the first time that a study of sound effects on the image is performed in terms of the cinematic art.

\section{Materials and Methods}

\subsection{Using a Film Sequence as a Research Tool}

A three minutes sequence from the film "Elephant" directed by G. Van Sant [21] was selected as a methodological tool for the conduction of our study. The sequence is composed by two steadicam shots, during which we follow a young man walking in a college / high school campus. The sound designer of this original version (from now on called "version 1") was Leslie Shatz, who developed a dramatic / poetic synthesis for the sequence, in which non diegetic, sad piano-music was the dominant element. Besides version 1, two different soundtracks were composed for the same sequence. For "version 2" we composed a dramatic realistic soundtrack, using natural sounds of the environment (eg. voices, rain, vehicles etc) and excluding any sound sources out of the sequence's reality. For "version 3" we composed a comic soundtrack including natural "gang-sounds", eg the funny voice of somebody singing, or animal sounds, again excluding non-diegetic sound sources.

\subsection{Sample and Experimental Procedure}

The above products of audiovisual synthesis were used as a methodological tool for the following research: The three versions of the sequence were screened to 51 adult students (mean age 21.3 y.o., Table 1) of the Departments of Film Studies (32 students) and Biology (19 students) of Aristotle University of Thessaloniki, Greece. Two separate screenings took place, each one for the students of each department. During screening, the sequences' order was different in the two groups of spectators.

Before the screening, all the individuals were asked for possible disabilities in hearing and seeing. The viewers were asked to write their answers on a series of questions they were given after each screening within five minutes (see Appendix for further details on the questionnaire's format). The same set of questions, was given after each screening. No hearing or seeing disabilities were mentioned by the subjects, so all the 51 questionnaires were taken into account for the rest of the analyses. The most important of the findings after collecting and processing the data, follow in the next session.
Table 1. Sample ID. Differences between left- and right-handed as well as between individuals who have and have not seen the movie could not be detected due the extra small participation of left handed and having seen the movie individuals.

\begin{tabular}{|c|c|}
\hline Total subjects & 51 \\
\hline Men & 21 \\
\hline Women & 30 \\
\hline Students in film department & 32 \\
\hline Students in biology department & 19 \\
\hline Students who play an instrument & 20 \\
\hline Students who don't play an instrument & 31 \\
\hline Right handed & 45 \\
\hline Left handed & 6 \\
\hline Have seen the movie & 4 \\
\hline Haven't seen the movie & 47 \\
\hline
\end{tabular}

\section{Conclusions}

Concerning the identification of the film gender, versions 1 and 2 were characterized as "drama films" by more than three quarters of the subjects in both experiment groups. However, version 3 (comedy soundtrack) was characterized as "drama film" or "comedy" by almost equal parts (near $40 \%$ ) of the sample in both groups. This could mean that elements of drama and realism are easier identified by the film viewers, compared to comedy. This is also supported by the finding that the majority of subjects in both groups (more than $80 \%$ for both cases) selected version 2 as the original soundtrack of the sequence.

The time (season) in the film-world was found to be determined mainly by visual than auditory elements of the sequence for the majority of the subjects. Visual elements also determined the viewers' perception of the sequence crucial moment in all groups.

The emotions of the protagonist, according to the viewers' approach, were different in the three versions of the sequence and in most cases they were similar to the emotions of the viewers.

Sound design was able to create visual illusions. In both versions 2 and 3, there was a part of the sample that "saw" elements that were not on the screen, but existed only as sounds. It seemed that women, students of biology and individuals without knowledge of an instrument were mainly subjected to this kind of illusion.

We conclude that, although different parameters of the sequence (film gender, crucial moment, emotions etc) are not equally affected when the sound band is changed, the sound remains a dynamic quality of the cinematic aesthetics, which can be manipulated in order to cause a different perception by the viewers.

Finally, it is possible that the changes in the sound design affect in a different way individuals from different groups. The gender (sex), field of studies and the knowledge of an instrument might be some of the cause factors of these differences. 


\section{Appendix}

Experiment Questionnaire Sample

A. Sample Identification Questions

1. Age:

2. Sex:

male

female

3. Country of origin:

4. Mother language:

5. Institution:

6. Year of studies:

7. Field of studies:

Humanities

Science and applied science

Arts

8. You write using:

your right hand

your left hand

both hands

9. You have any kind of vision deficiency?

no

yes

10. You have any kind of hearing deficiency?

no

yes

11. You play any musical instrument?

no

yes

12. How often do you watch movies?

daily

2-3 times / week

once per week

1-2 times per month

less than once a month

13. You watch movies:

at cinema

on tv

on pc / laptop

on mobile phone

elsewhere:

14. You mainly like watching (1 choice):

thrillers

fantasy movies

adventures

comedies

dramas

documentaries

Animation 
15. Rate the following movies $\underline{O N L Y}$ if you have watched them (1: really bad - 10: great)

- The seventh seal

- Requiem for a dream

- Lost highway

- Dark night

- Amelie

- Tristana

- Psycho

B. Experiment Questions

1. Which is the gender of the movie?
thriller
fantasy movie
adventure
comedy
drama
documentary

2. How did you feel during the screening? (give a rating for ALL the cases)

\begin{tabular}{lcccccccccc} 
& not at all & & & & & & \multicolumn{3}{c}{ very much } \\
gladness & 1 & 2 & 3 & 4 & 5 & 6 & 7 & 8 & 9 & 10 \\
relief & 1 & 2 & 3 & 4 & 5 & 6 & 7 & 8 & 9 & 10 \\
confusion & 1 & 2 & 3 & 4 & 5 & 6 & 7 & 8 & 9 & 10 \\
emotion & 1 & 2 & 3 & 4 & 5 & 6 & 7 & 8 & 9 & 10 \\
surprise & 1 & 2 & 3 & 4 & 5 & 6 & 7 & 8 & 9 & 10 \\
fear & 1 & 2 & 3 & 4 & 5 & 6 & 7 & 8 & 9 & 10 \\
anxiety & 1 & 2 & 3 & 4 & 5 & 6 & 7 & 8 & 9 & 10 \\
disappointment & 1 & 2 & 3 & 4 & 5 & 6 & 7 & 8 & 9 & 10 \\
indifference & 1 & 2 & 3 & 4 & 5 & 6 & 7 & 8 & 9 & 10
\end{tabular}

3. The main character of the scene seemed to be (give a rating for ALL the cases):

\begin{tabular}{lcccccccccc} 
& not at all & & & & & \multicolumn{3}{c}{ very m } \\
dynamic & 1 & 2 & 3 & 4 & 5 & 6 & 7 & 8 & 9 & 10 \\
cheerful & 1 & 2 & 3 & 4 & 5 & 6 & 7 & 8 & 9 & 10 \\
anxious & 1 & 2 & 3 & 4 & 5 & 6 & 7 & 8 & 9 & 10 \\
surprised & 1 & 2 & 3 & 4 & 5 & 6 & 7 & 8 & 9 & 10 \\
gentle & 1 & 2 & 3 & 4 & 5 & 6 & 7 & 8 & 9 & 10
\end{tabular}

4. During the screening, you saw on screen:

A police car

A helicopter

A train

A woman coughing

Birds

A man shooting with a gun

A bicycle

Ducks

5. During the screening, you heard:

A police car

A bell ringing

A helicopter

A train

A woman coughing

Birds

A chorus

A bicycle

Ducks 
6. Which is the dominant color of the scene? (ONE choice)

white

black

yellow

red

green

blue

other:

7. Do you remember any words you heard during the screening?

8. $\alpha$. Was there music in the scene?

yes

no

ק. If yes, you would say that this music was: not at all $\begin{array}{lllllllllll}\text { slow } & 1 & 2 & 3 & 4 & 5 & 6 & 7 & 8 & 9 & 10\end{array}$

$\begin{array}{lllllllllll}\text { fast } & 1 & 2 & 3 & 4 & 5 & 6 & 7 & 8 & 9 & 10\end{array}$

$\begin{array}{lllllllllll}\text { joyful } & 1 & 2 & 3 & 4 & 5 & 6 & 7 & 8 & 9 & 10\end{array}$

$\begin{array}{lllllllllll}\text { depressing } & 1 & 2 & 3 & 4 & 5 & 6 & 7 & 8 & 9 & 10\end{array}$

9. $\alpha$. Did the scene remind you of any movie you have seen before?

yes

no

\section{$\beta$. If yes, which movie?}

10. The scene was:

$\begin{array}{ccccccccccc}\text { slow } & & & & & & & & & \text { fast } \\ 1 & 2 & 3 & 4 & 5 & 6 & 7 & 8 & 9 & 10\end{array}$

11. What is your general opinion about the scene? I din't like it at all

$\begin{array}{llllllllll}1 & 2 & 3 & 4 & 5 & 6 & 7 & 8 & 9 & 10\end{array}$

12. Would you like to see the rest of the movie?

yes

no

13. What is the season the sequence takes place?

winter

spring

summer

autumn

\section{REFERENCES}

[1] P. Shimamura. Psychocinematics: Issues and directions. In Psychocinematics: Explorations in cognition at the movies, Oxford University Press, New York, 2013.

[2] J. C. Hay, H. L. Pick, K. Ikeda). Visual capture produced by prism spectacles, Psychonomic Science, Vol.2, 215-216.

[3] I. P. Howard, W. B. Templeton. Human spatial orientation. Wiley, New York, 1966.

[4] P. Bertelson, G. Aschersleben. Automatic visual bias of

perceived auditory location. Psychonomic Bulletin \& Review, Vol.5, 482-489.

[5] N. Kitagawa, S. Ichihara. Hearing visual motion in depth. Nature, Vol.416, 172-174.

[6] N. Kitajima, Y. Yamashita. Dynamic capture of sound motion by light stimuli moving in three-dimensional space. Perceptual and Motor Skills, Vol.89, 1139-1158.

[7] G. H. Recanzone. Auditory influences on visual temporal rate perception. Journal of Neurophysiology, Vol.89, 1078-1093.

[8] B. H. Repp, A. Penel. Auditory dominance in temporal processing: New evidence from synchronization with simultaneous visual and auditory sequences. Journal of Experimental Psychology: Human Perception and 
Performance, Vol.28, 1085-1099.

[9] S. E. Guttman, L. A. Gilroy, R. Blake. Hearing What the Eyes See: Auditory Encoding of Visual Temporal Sequences. Psychological Science, Vol.16, No.3, 228-235.

[10] A. Lahav, E. Saltzman, G. Schlaug. Action representation of sound: audiomotor recognition network while listening to newly acquired actions. Journal of Neuroscience, Vol.27, No.2, $308-314$.

[11] T. Thesen, Z. F. Jonas, Z. Vibell, A. Gemma, R. A. Calvert, A. Oesterbauer. Neuroimaging of multisensory processing in vision, audition, touch, and olfaction. Cognitive Processing, Vol.5, 84-93

[12] S. A. Iakovides, V. T. H. Iliadou, V. T. H. Bizeli, S. G. Kaprinis, K. N. Fountoulakis, G. S. Kaprinis. Psychophysiology and psychoacoustics of music: Perception of complex sound in normal subjects and psychiatric patients. Annals of General Hospital Psychiatry, Vol.3, 6.

[13] C. R. Kight, J. P. Swaddle. How and why environmental noise impacts animals: an integrative, mechanistic review. Ecology Letters, Vol.14, 1052-1061.

[14] D. Radin, G. Hayssen, M. Emoto, T. Kizu. Double blind test of the effects of distant intention on water crystal formation. Explore, Vol.2, No.5, 408-411.

[15] J. Samson, R. S. Devi, R. Ravindran, M. Senthilvelan. Effect of noise stress on free radical scavenging enzymes in brain. Environmental Toxicology and Pharmacology, Vol.20, $142-148$.

[16] A. P. Møller, J. P. Swaddle. Asymmetry, Developmental Stability, and Evolution. Oxford University Press, Oxford, 1997.

[17] T. R. Gest, M. I. Siegel, J. Anistranski. The long bones of neonatal rats stressed by cold, heat, and noise exhibit increased fluctuating asymmetry. Growth, Vol. 50, 385-389.

[18] L. Meyer. Emotion and meaning in music. Chicago University Press, Chicago, 1956.

[19] M. Chion. Audio-vision. Sound on screen. Columbia University Press, New York, 1990.

[20] D. Sonnenschein D. Sound design: The expressive power of music, voice and sound effects in cinema. M.Wiese Productions, California, 2001.

[21] Elephant [film] HBO Films, Fine Line Features, Meno Films. 2003. 